\title{
ANALISIS KINERJA, KUALITAS DATA, DAN USABILITY PADA PENGGUNAAN CAPI UNTUK KEGIATAN SENSUS/SURVEY
}

\author{
Takdir \\ Politeknik Statistika STIS \\ e-mail: takdir@stis.ac.id
}

\begin{abstract}
Abstrak
Pengumpulan data merupakan suatu tahapan pada Sensus/Survey yang sangat menentukan keberhasilan Sensus/Survey. Prosesnya yang memakan waktu lama akan mengakibatkan data yang disajikan tidak relevan dengan kondisi pada saat pelaksanaan. Dengan Computer-Assisted Personal Interview (CAPI), proses entri data dapat dilakukan pada saat proses interview berlangsung. Hal ini mempersingkat tahapan pengumpulan data hingga data tersedia pada sistem komputer dan siap untuk dianalisis. Pada penelitian ini, indikator-indikator penting penentu keberhasilan penerapan CAPI, yakni kinerja, kualitas data, dan usability diukur untuk melihat sejauh mana CAPI memberikan penyempurnaan pada pengumpulan data. Penelitian ini memberikan rekomendasi, baik dari segi konsep, maupun teknis, mengenai desain CAPI untuk kegiatan sensus/survey.
\end{abstract}

Kata kunci: $C A P I$, sensus, survey, pengumpulan data

\begin{abstract}
Data collection is a phase in census/survey phases which highly affect the success of cencus or survey. Using Computer-Assisted Personal Interviewing (CAPI), data entry could be carried out during interview. It could shorten the data collection stage until data were available on a computer system and ready for analysis. In this study, the essential indicators which determine the success of CAPI implementation, i.e. performance, data quality, and usability are mesured to undestand the signifacancy of CAPI in improving data collection. This study proposed recommendation, either in the aspect of concept, or technical regarding CAPI design for census/survey.
\end{abstract}

Keywords: CAPI, census, survey, data collection 


\section{PENDAHULUAN}

Data yang berkualitas sangat menentukan kebijakan pembangunan Negara dari berbagai arah, baik melalui kebijakan atau keputusan pemerintah secara langsung, maupun rekomendasi dari kegiatan penelitian. Badan Pusat Statistik (BPS) merupakan lembaga Negara yang ditugaskan khusus untuk menyediakan data statistik dasar yang dijadikan acuan oleh berbagai kalangan. Oleh karena itu, BPS dituntut untuk menjamin kualitas data yang dihasilkan.

Kegiatan Sensus dan Survey merupakan kegiatan pokok yang dilakukan oleh BPS. Tahapan pengumpulan data (data collection) merupakan salah satu tahapan pada kegiatan Sensus dan Survey yang harus dilaksanakan dan sangat menentukan keberhasilan pelaksanaan Sensus dan Survey. Tahapan pengumpulan data bertujuan untuk memperoleh data dan informasi dari responden, misalnya dengan melakukan wawancara secara langsung kepada responden. Tahapan ini sangat mempengaruhi kualitas data yang dihasilkan. Sebagai contoh, kesalahan perekaman data (data entry) akan mengakibatkan analisis data menghasilkan output yang tidak objektif. Selain itu, proses pengumpulan data yang memakan waktu yang lama akan mengakibatkan data yang nantinya disajikan tidak relevan dengan kondisi pada saat pengumpulan data dilakukan.

$$
\text { Computer-Assisted Personal }
$$

Interview (CAPI) merupakan sebuah terobosan pada tahapan pengumpulan data. Dengan CAPI, proses interview dengan responden dan entri data dilakukan secara bersamaan. Hal ini akan mempersingkat tahapan pengumpulan data hingga data tersedia pada sistem komputer. Dengan demikian, dengan penerapan CAPI yang tepat, dapat dilakukan efsiensi, baik dari segi biaya, maupun waktu yang dibutuhkan pada tahapan pengumpulan data.

Saat ini teknologi pendukung CAPI telah berkembang pesat dan telah banyak diterapkan di berbagai Negara maju, khususnya Amerika, Inggris, Australia, dan
Selandia Baru. Indonesia sebagai Negara dengan peringkat 4 jumlah penduduk terbesar di dunia (CIA World Factbook 2013) memerlukan solusi untuk memudahkan pengumpulan data agar kegiatan sensus/survey dapat berjalan lebih optimal.

Sekolah Tinggi Ilmu Statistik (STIS) merupakan perguruan tinggi kedinasan yang didirikan oleh BPS untuk memenuhi kebutuhan sumber daya manusia dalam menjalakan kegiatan perstatistikan di BPS. Setiap tahunnya STIS mengadakan kegiatan Praktil Kerja Lapangan (PKL) bagi mahasiswa semester ke-5 sebagai miniatur kegiatan perstatistikan yang dilakukan BPS. Penelitian ini bertujuan untuk mengukur kinerja, kualitas data yang dihasilkan, serta usability (kemudahan penggunaan) pengumpulan dan perekaman data dengan menggunakan CAPI. PKL Angkatan 54 STIS yang menggunakan 2 jenis metode/alat pengumpulan data, yakni PAPI (Paper-and-pencil Personal Interview dan CAPI, merupakan objek studi kasus yang akan diteliti. Untuk melengkapi hasil analisis, dilakukan perbandingan antara PAPI dan CAPI pada variabel-variabel yang dapat diperbandingkan, yakni kinerja dan kualitas data. Hasil penelitian menunjukkan bahwa CAPI memiliki potensi untuk diterapkan sebagai alat penumpulan dan perekaman data pada sensus/survey karena memiliki sejumlah kelebihan dari beberapa aspek. Aspek-aspek yang perlu menjadi perhatian utama dalam penerapan CAPI juga disajikan pada hasil penelitian ini. Selain itu, penelitian ini memberikan rekomendasi desain CAPI yang tepat, baik dari segi hardware maupun software, untuk diterapkan untuk di BPS pada survey yang memiliki kesamaan karakteristik dengan objek studi kasus pada penelitian ini, serta bentuk dukungan yang sesuai untuk diberikan kepada pengguna CAPI oleh organisasi.

\section{TINJAUAN REFERENSI}

\section{Sejarah CAPI}

Pada tahun Oktober 1988, Bureau of Census Amerika membentuk sub komite 
yang membidangi Computer Assisted Survey Information Collection (CASIC) untuk meneliti potensi kemajuan di bidang teknologi untuk keperluan pengumpulan data statistik, transmisi data ke pusat data, dan masalah (issue) pada proses implementasinya (Bishop et al. 1990). Komite tersebut melakuan sejumlah studi mengenai teknologi-teknologi pengumpulan data yang memungkinkan untuk digunakan, khususnya CATI (Computer-Assisted Telephone Interview) dan CAPI. CAPI merupakan pengembangan dari $C A T I$ yang sebelumnya telah menjadi standard alat pengumpulan data dalam bidang penelitian (Bishop et al. 1990). Kemunculan metode CAPI dikuti dengan berbagai produk teknologi sebagai implementasi dari CAPI, seperti Prepared Data Entry (PDE), Touchtone Data Entry (TDE), dan Voice Recognition Entry (VRE) (Bishop et al. 1990).

Tahun 1989, Bureau of Census Amerika menggunakan CAPI pada Current Population Survey (CPS) (Couper and Geraldine Burt 1989). UK Labour Force Survey tahun 1990 merupakan survey berskala besar yang dilakukan OPCS (Office of Population Censuses and Surveys), yakni kantor statstik pemerintah Inggris, yang pertama kali menggunakan laptop untuk wawancara tatap muka (Matheson 1991). Pada sektor komersil, British Telecom's juga telah menggunakan CAPI untuk survey kepuasan pelanggan pada tahun 1990 (Sainsbury, Ditch, and Hutton 1993). Namun, survey di bidang sosial masih sedikit yang menggunakan CAPI. Hal ini disebabkan karena CAPI masih tergolong baru dan dianggap belum matang (mature), serta membutuhkan biaya awal yang tergolong besar (Sainsbury et al. 1993).

Beberapa report papers dan penelitian terbaru, misalnya (Shaw, Nguyen, and Nischan 2011) dan (Cavigliaharris et al. 2012), telah menunjukkan penggunaan dan pengembangan CAPI secara intensif. Di STIS, sistem CAPI telah digunakan pada kegiatan Praktik Kerja Lapangan (PKL) mahasiswa STIS sejak tahun 2011. Dimulai dengan aplikasi berbasis web yang memiliki kemampuan offline storage, hingga dalam bentuk aplikasi smartphone native seperti sekarang ini. CAPI yang dikembangkan di STIS terus mengalami pengembangan dari tahun ke tahun dan diuji melalui kegiatan PKL. Namun, sayangnya, CAPI belum dimanfaatkan secara optimal di Indonesia, khususnya di BPS. Penelitian mengenai CAPI di Indonesia juga sangat sedikit sehingga belum ada rujukan yang meyakinkan pihak yang berkepentingan untuk digunakan sebegai pengganti PAPI. Hal tersebut terlihat dari minimnya literatur ilmiah maupun laporan yang dapat diakses yang membahas penggunaan $C A P I$ dalam melakukan survey. Penelusuran dengan kata kunci terkait CAPI dan "Indonesia" pada search engine dan repository karya ilmiah online tidak dapat memberikan hasil yang relevan dan pembahasan khusus terkait CAPI, begitu pula dengan daftar pustaka serta daftar tulisan ilmiah yang melakukan sitasi terhadap artikel-artikel populer yang membahas $C A P I$, yang juga terdapat pada daftar pustaka tulisan ini.

\section{Kelebihan dan Kekurangan CAPI}

Penerapan CAPI dengan tepat akan memberikan dampak positif berupa kualitas data yang lebih baik (better quality), durasi yang lebih cepat (improved speed), dan biaya operasional yang lebih rendah (lower cost) dibandingkan dengan metode PAPI (Manners 1990).

\section{Better Quality}

1. Adanya fitur automatic routing pada kuesioner yang didukung oleh CAPI menyebabkan kejadian missing value hanya akan terjadi apabila responden tidak ingin memberikan jawaban, bukan karena kesalahan interviewer yang melewatkan pertanyaan (Manners 1990).

2. Pada CAPI pengecekan konsistensi dan validitas isian dilakukan secara otomatis, sedangkan pada PAPI, hal tersebut dilakukan secara manual yang rentan terhadap kesalahan (Manners 1990). 
3. Kalkulasi matematis diikutkan pada saat pencacahan sehingga penghitungan dapat dilakukan dengan komputer yang memberikan hasil akurat (Sainsbury et al. 1993).

4. Kesalahan (error) pada saat perekaman data yang diakibatkan oleh program data entri yang terpisah dengan kuesioner pada PAPI dapat dihindari (Sainsbury et al. 1993).

\section{Improved Speed}

Proses editing dokumen dan data entry yang membutuhkan alokasi waktu tersendiri pada metode PAPI tidak ditemui pada penerapan CAPI. Penerapan CAPI juga memungkinkan untuk mengirimkan data ke pusat data secara langsung pada saat pencacahan dilakukan sehingga pemrosesan data untuk tahapan selanjutnya dapat segera dilakukan (Manners 1990).

\section{Lower Cost}

Penghematan biaya pada CAPI dapat dicapai dengan 3 hal (Manners 1990). Pertama, tidak membutuhkan server dan mainframe dalam jumlah yang banyak untuk mendukung infrastruktur pengentrian data. Kedua, biaya yang diperlukan untuk proses editing dokumen dan pengentrian data dapat dihindari. Ketiga, kuesioer yang dikonversi ke dalam sistem komputer dapat diakses dan digunakan langsung dengan mudah oleh interviewer sehingga mengurangi jumlah tenaga spesialis komputer dan programmer (Manners 1990).

Disamping kelebihan tersebut, CAPI juga memiliki kelemahan-kelemahan yang secara umum dapat dijelaskan sebagai berikut (Matheson 1991).

\section{Biaya Setup}

Diperlukan biaya yang besar untuk investasi awal pada $C A P I$, khususnya untuk pengadaan infrastruktur.

\section{Keterbatasan Device dan Kompleksitas}

Keterbatasan device, misalnya dari segi ukuran, yang digunakan pada CAPI secara langsung juga memberikan dampak keterbatasan pada metode CAPI itu sendiri.

\section{Pertanyaan Terbuka}

CAPI memiliki kesulitan untuk menangani pertanyaan terbuka karena membutuhkan coding tertentu.

\section{Kualitas Data}

Selain memiliki kelebihan dari sisi kualitas data, CAPI juga memiliki kelemahan yang dapat mempengaruhi kualitas data. Apabila tedapat pertanyaan yang memiliki validasi yang strict (harus diisi) pada CAPI namun jawabannya tidak diketahui oleh responden, hal tersebut akan membuat interviewer mengisikan jawaban yang tidak sesuai agar dapat melanjutkan ke pertanyaan selanjutnya.

\section{Kesalahan Perekaman Data}

Apabila terjadi kesalahan pencacah dalam menginputkan data, sulit untuk menelusuri nilai yang benar untuk memperbaikinya karena dokumen (kuesioner kertas) tidak tersedia.

\section{Issue pada Penerapan $C A P I$}

Dalam perkembangannya, dengan model dan kebutuhan survey yang beragam, terdapat berbagai issue pada penerapan CAPI untuk melakukan pengumpulan data (Matheson, 1991). Issue tersebut merupakan hal yang perlu dipertimbangkan ketika akan mengimplementasikan CAPI.

\section{Concurrent Interviewing}

Pada kasus jumlah anggota rumah tangga yang akan dicacah cukup banyak, pencacah memiliki alternatif dengan membacakan pertanyaan cukup sekali dan dijawab bergantian oleh para responden. Perlu alternatif untuk melakukan hal yang sama pada $C A P I$.

\section{Flexibility}

Pencacah terkadang harus kembali ke pertanyaan atau blok (kelompok pertanyaan) sebelumnya untuk mengisi menanyakan kembali pertanyaan yang terlewatkan. Desain CAPI yang menampilkan pertanyaan satu per satu secara sequensial dapat menyulitkan melakukan hal ini. Oleh karena itu, desain yang baik perlu mengantisipasi hal ini. 


\section{Data Quality}

Automatic routing (mengarahkan pertanyaan secara otomatis) merupakan salah satu fitur CAPI untuk meningkatkan kualitas data. Namun, fitur ini juga dapat berdampak negatif. Misalnya ketika pencacah salah melakukan input, maka akan diarahkan ke pertanyaan yang salah pula. Penggunaan fitur ini perlu memperhatikan kasus tersebut yang mungkin terjadi.

\section{Diary Processing}

Perlu dipertimbangkan untuk disediakan catatan tersendiri pada saat pencacahan dengan CAPI yang terpisah dengan kuesioner untuk mencatat hal-hal yang tidak dapat ditangani dengan mudah oleh CAPI.

\section{Respondent/Interviewer Acceptability}

Perlu diteliti lebih lanjut apakah responden bersedia datanya, termasuk data pribadi dan sensitif, dientrikan langsung ke sistem komputer. Kesediaan dan kemampuan pencacah untuk menggunakan device pendukung CAPI juga harus menjadi pertimbangan.

\section{Timetable}

Susunan jadwal
sensus/survey juga perlu didesain
sedemikian rupa menyesuaikan dengan
CAPI. Sistem komputer mengharuskan
jadwal yang pasti dan setiap tahapan harus
dijabarkan dengan detail.

\section{Indikator Kinerja Interviewer pada CAPI}

Pada PAPI, pengukuran kinerja interviewer dapat berupa variabel response rates, accuracy rates, dan production rates (Couper and Geraldine Burt 1989). Namun, CAPI membutuhkan indikator yang berda untuk mengukur kinerja interviewer karena beberapa indikator yang dipengaruhi oleh keterbatasan interviewer dapat ditangani oleh sistem komputer. Couper dan Geraldine merupakan peneliti yang pertamakali mengusulkan 3 indikator yang dapat digunakan untuk mengukur kinerja interviewer pada CAPI sebagai berikut (Couper and Geraldine Burt 1989).

1. Drop-out Rates, yaitu mencatat jumlah kasus di mana interviewer secara sepihak memutuskan berhenti untuk melakukan pencacahan. Indikator ini bertujuan untuk melihat sikap interviewer dalam menghadapi teknologi terkomputerisasi.

2. Data Quality Indicators, yaitu jumlah non-response dan penolakan oleh responden terhadap interviewer.

3. Self-reports of difficulties with CAPI, yaitu berdasarkan laporan kesulitan yang dihadapi oleh interviewer dalam menggunakan CAPI. Kesulitan dapat berupa aspek hardware, software, penanganan kasus khusus, dan jaringan komunikasi.

\section{Durasi Interview pada CAPI dan PAPI}

Durasi interview merupakan salah satu pertimbangan penting untuk menerapkan CAPI. Beberapa penelitian telah dilakukan untuk membandingkan durasi interview pada metode PAPI dan CAPI. Penelitan-penelitian tersebut memberikan hasil yang berbeda-beda. Beberapa diantara memberikan hasil bahwa PAPI memiliki durasi yang lebih lama (Baker, 1992; Baker et al, 1994; Lynn and Purdon, 1994), dan ada pula yang memberikan hasil yang sebaliknya (Martin and collegues, 1993; Muller and Kesselmann, 1996). Hasil yag komprehensif ditunjukkan pada penelitian Fuch (Fuchs, Couper, and Hansen 2000) dengan mengidentifikasi faktor-faktor yang mempengaruhi durasi interview pada metode PAPI dan CAPI. Terdapat 4 poin penting yang menyebabkan perbedaan durasi interview antara PAPI dan CAPI (Fuchs et al. 2000), yaitu:

\section{Loop Design}

Loop design pada umumnya diterapkan pada CAPI di mana responden diinterview satu per satu. Tiap responden harus menyelesaikan sebuah kuesioner sebelum menanyakan pertanyaan ke responden lainnya. Hal yang berbeda bisa dilakukan pada PAPI untuk rumah tangga 
yang memiliki banyak jumlah anggota rumah tangga di mana setiap anggota rumah tangga diinterview secara bersamaan. Loop design berkaitan degan concurrent interviewing pada pembahasan sebelumnya.

\section{Character Input and Banked Screens}

Proses input data pada CAPI mengharuskan interviewer mengentrikan data sesuai dengan logic kuesioner CAPI. Hal ini berbeda dengan PAPI yang memungkinkan interviewer lebih bebas menuliskan data. Misalnya dalam kasus interviewer diharuskan menginputkan nama depan (first name) dan nama belakang (last name) pada CAPI yang membutuhkan waktu bagi interviewer untuk menentukan kedua fields tersebut.

\section{Automated Calculations and Fills}

Salah satu kelebihan CAPI adalah, interviewer dapat melakukan perhitungan yang rumit dengan memanfaatkan device yang dibawa secara otomatis, misalnya menghitung umur berdasarkan tanggal lahir yang diperoleh.

\section{"Real" Comparison}

Interviewer terkadang membacakan list/daftar anggota rumah tangga untuk meakukan konfirmasi dan memastikan tidak ada anggota rumah tangga yang tidak tercatat. Hal ini juga mempengaruhi perbedaan durasi waktu interview antara PAPI dan CAPI.

\section{Kualitas Data}

Diperlukan dasar yang kuat untuk megukur kualitas data yang dihasilkan pada CAPI. Ukuran yang digunakan sebisa mungkin tidak dipengaruhi oleh faktor diluar pengaruh penggunaan CAPI itu sendiri. Model yang dikembangkan De Leeuw (De Leeuw, 1992) mengenai efek pengumpulan data terhadap kualitas data merupakan model yang banyak drujuk untuk mengukur kualitas data yang dihasilkan dengan menerapkan CAPI.

Dalam peneitian yang lain (Sainsbury, Ditch, and Hutton 1995) yang membahasa model De Leeuw, dinyatakan pula bahwa terdapat 3 faktor pada CAPI, yaitu faktor teknologi/program, kehadiran (presence) perangkat komputer, dan efek penggunaan CAPI terhadap situasi pada saat interview seperti pada Error! Reference source not found.

\section{Spesifikasi Teknis Software dan Hardware CAPI}

CAPI merupakan penerapaan teknologi komputer untuk memudahkan proses pengumpulan data pada Survei/Sensus. Oleh karena itu, spesifikasi teknis, seperti ukuran dan berat perangkat, jenis dan mekanisme pengentrian data, ketahanan baterai, jenis dna resolusi monitor, serta pemilihan software yang digunakan perlu ditentukan dengan tepat. Berikut adalah beberapa penelitian terkait yang mengusulkan spesifikasi teknis untuk penerapan CAPI (Caviglia-harris et al. 2012).

1. Couper and Groves (1992) menyimpulkan bahwa berat hardware yang digunakan merupakan faktor terpenting bagi interviewer. Dari pengujian menggunakan beberapa jenis komputer, mereka menemukan bahwa ukuran berat yang nyaman untuk dibawa adalah 7-8 pounds (kurang lebih 3-4 kilogram), sedangkan untuk pencacahan dengan keadaan berdiri hanya seberat 3 pounds (kurang lebih 1,4 kilogram).

2. Studi lain (Baker et al, 1995) menyebutkan bahwa kesulitan menginput data pada desain CAPI yang hanya menyertakan satu atau sedikit pertanyaan dalam satu kali tampilan di monitor, dan kesulitan membaca monitor di perangkat pada kondisi pencahayaan yang tidak baik merupakan 2 faktor yang menyebabkan durasi interview dengan CAPI lebih lama daripada $P A P I$.

3. Penelitian lain meghasilkan CAPI memberikan durasi interview yang lebih cepat dibandingkan dengan PAPI ketika interface dan desain survey ditetapkan dengan baik. Hal tersebut meliputi automatic skip, perhitungan aritmatika, dan desain survey yang kompleks (Couper 2000). 


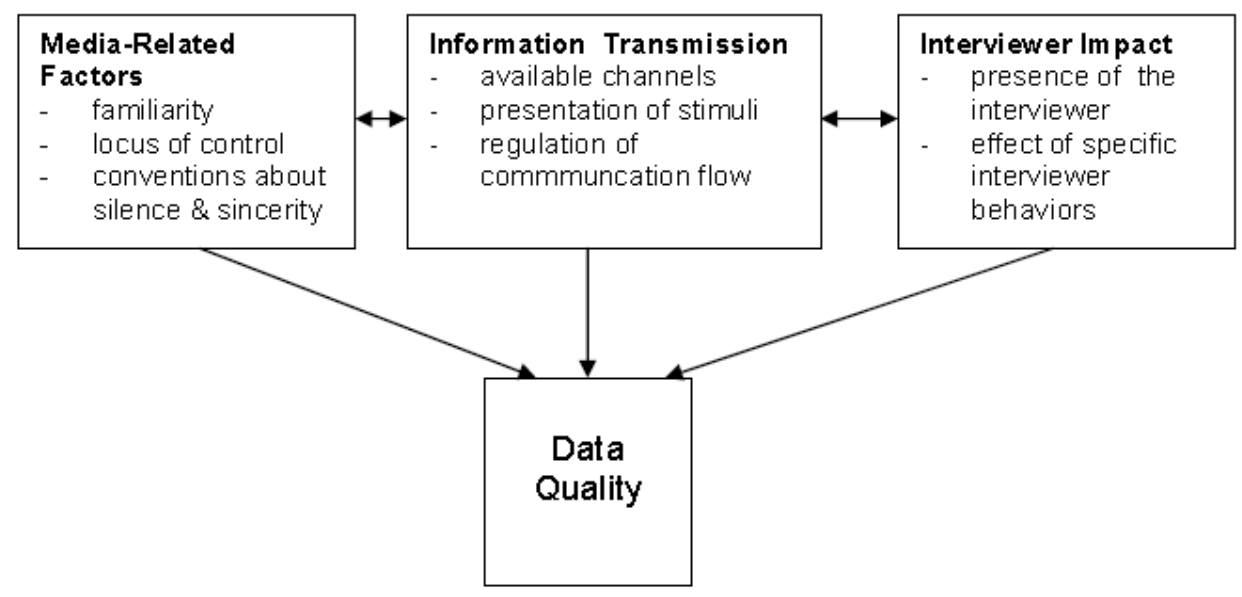

Gambar 1. De Leeuw's Conceptual Model of Data Collection Effects on Data Quality (Randolph et al. 2006)

4. PDA (Personal Digital Assistance) merupakan device yang paling sering dipilih untuk CAPI karena peprtimbangan berat, ukuran, dan biaya (Bernabe-Ortiz et al. 2008).

5. Untuk survey dengan desain yang kompleks, ukuran layar yang lebih besar (laptop) memberikan keuntungan yang signifikan dibadingkan dengan PDA (Childs and Landreth 2006).

Berdasarkan hasil penelusuran penulis terhadap sejumlah aplikasi CAPI yang tersedia baik secara gratis maupun komersial, diperoleh sejumlah produk yang telah populer dan banyak digunakan oleh berbagai kalangan, baik organisasi swasta, pemerintah, maupun peneliti. Diantaranya adalah BLAISE yang di-develop oleh Statistics Netherland, CSPro yang didevelop oleh United States Census Bureau, Survey Solutions yang di-develop oleh World Bank, OpenDataKit oleh University of Washington's Department of Computer Science and Engineering, dan KoBoToolbox oleh Harvard Humanitarian Initiative. OpenDataKit dan KoBoToolbox bersifat opensource, CSPro bersifat freeware, sedangkan software lainnya memiliki model lisensi komersil yang beragam.

\section{Usablity}

Untuk melihat tingkat kegunaan dan kenyamanan pengguna (interviewer) dalam melakukan pengumpulan data dengan CAPI, diperlukan pengukuran kepuasan pengguna terhadap desain CAPI yang dibuat. Terdapat berbagai metode yang dapat digunakan untuk melakukan pengukuran tersebut. Salah satu tools yang sudah mature dan banyak digunakan adalah QUIS (Questionnaire for User Interaction Satisfaction) (Slaughter, Harper, and Norman 1994). QUIS digunakan untuk assessment kepuasan pengguna secara subjektif dengan aspek yang spesifik, yakni dari segi antar-muka (interface).

\section{Kerangka Pikir}

Dalam mengkaji penerapan CAPI pada survey, sejumlah aspek yang berpengaruh menjadi perhatian dalam penelitian ini. Kerangka pikir yang menjadi acuan dalam penelitian ini dapat dilihat pada Gambar 2 berikut.

Untuk melihat aspek yang perlu diperhatikan dalam melakukan transisi dari survey berbasis PAPI ke CAPI, dilakukan studi literatur dengan tema sumber literatur berupa kajian dan hasil penerapan CAPI dari berbagai negara, perusahaan, dan NSO (National Statistics Office) dalam kurun waktu 15 tahun terakhir. Dari studi literatur diperoleh sejumlah variabel yang dapat dikategorikan menjadi 3 jenis, yakni performance, data quality, dan usability. Ketiga variabel tersebut kemudian menjadi acuan untuk melakukan evaluasi pada pilot study yang dilakukan melalui kegiatan PKL 


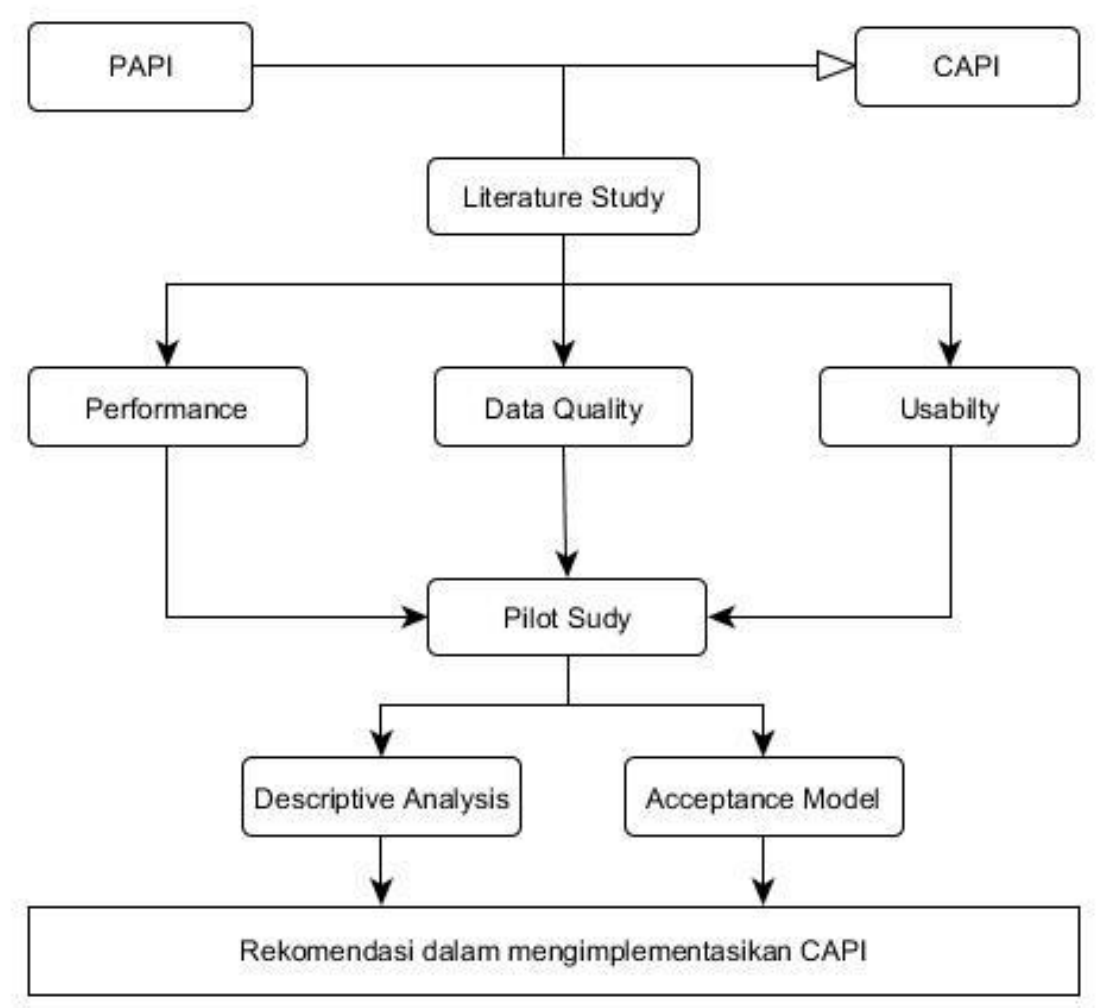

Gambar 2. Kerangka Pikir Penelitian

54 dan 55 STIS. Data yang dihasilkan dari evaluasi diolah dengan analisis deskriptif dan Technology Acceptance Model (TAM) untuk menghasilkan rekomendasi, khususnya untuk BPS, dalam mengimplementasikan CAPI. Analisis dengan TAM diluar pembahasan paper ini.

\section{METODOLOGI}

\section{Objek dan Metode Penelitian}

Penelitian ini merupakan pilot study dengan objek studi kasus Praktik Kerja Lapangan (PKL) Angkatan 54 dan 55 Sekolah Tinggi Ilmu Statistik. PKL 54 dan 55 STIS menggunakan 2 metode pencacahan yaitu pencacahan menggunakan kuesioner kertas $(P A P I)$ dan menggunakan kuesioner elektronik (CAPI). Pada PKL 54 jumlah interviewer yang menggunakan CAPI sebanyak 108 orang atau 26,21 persen dari jumlah interviewer pada PKL 54, sedangkan pada PKL 55 sebanyak 228 orang atau 49 persen dari jumlah interviewer pada PKL 55. Adapun jumlah sampel yang dicacah dengan CAPI pada PKL 54 adalah sebanyak 1.755 responden atau 21,49 persen dari jumlah sampel, sedangkan pada PKL 55 sebanyak 3.406 responden atau 60 persen dari jumlah sampel.

Perangkat pendukung pencacahan CAPI berupa tablet/smartphone berbasis Android ${ }^{\circledR}$ yang disesuaikan dengan kebutuhan aplikasi untuk pencacahan. Setiap tim pencacah menerima empat buah tablet, tiga tablet digunakan oleh Petugas Cacah Lapangan (PCL) dan satu tablet untuk koordinator tim yang berfungsi sebagai perangkat cadangan dan perangkat pendukung monitoring.

Pada PKL 54, aplikasi CAPI yang digunakan masih bersifat statis, yaitu aplikasi didesain untuk tujuan survey yang spesifik pada PKL tersebut saja, sehingga untuk diterapkan pada survey lain atau PKL selanjutnya harus dilakukan perubahan kode program secara menyeluruh (hardcode). CAPI yang digunakan pada PKL 55 telah mengadopsi sistem kuesioner dinamis, daimana aplikasi dikembangkan berbasis software opensorce OpenDataKit. Dengan demikian, perubahan kuesioner dapat dilakukan dengan cepat tanpa harus mengubah kode sumber dari aplikasi CAPI. Selain itu, inovasi berupa proses listing 
berbasis CAPI juga diterapkan pada PKL 55 dengan mengembangkan modul listing pada aplikasi CAPI. Frame hasil listing kemudian akan menghasilkan sampel responden terpilih secara otomatis dengan menambahkan fitur penarikan sampel otomatis pada sisi server. Sampel yang terpilih akan didistribusikan ke device pencacah berupa kuesioner elektronik yang siap digunakan untuk mencacah responden.

\section{Variabel yang Diteliti}

Terdapat sejumlah variabel yang mempengaruhi kualitas CAPI untuk diterapkan sebagai tools pengumpulan data. Pada penelitian ini, penulis mengategorikan variabel-variabel yang diteliti menjadi 3 kategori, yakni performance, data quality, dan usability.

\section{Performance}

Dalam dunia teknologi informasi, performance memiliki cakupan yang luas. Namun, untuk memudahkan analisis dan pendalaman masalah, penulis menetapkan beberapa variabel yang termasuk dalam kategori performance yang diperoleh dari studi literatur dengan penyesuaian terhadap kondisi studi kasus, yaitu durasi pencacahan hingga raw data siap untuk dianalisis, keluhan/laporan kerusakan, serta kinerja sistem yang meliputi software dan hardware, baik pada sisi client, maupun server.

\section{Data Quality}

Ukuran kualitas data mengacu pada hal-hal yang menyebabkan data yang dikumpulkan tidak valid atau memiliki anomali sehingga tidak merepresentasikan kenyataan sebenarnya. Untuk mengukur kualitas data yang bersifat laten/abstrak secara lengkap perlu memperhatikan berbagai aspek, sehingga tidak mudah untuk menarik kesimpulan absolut mengenai kualitas data. Untuk itu, perlu dibatasi variabel yang akan dipantau yang dapat dijadikan representasi terbaik untuk mewakili kualitas data. Pada penelitian ini, kualitas data diwakili oleh beberapa variable yang telah diterapkan pada $C A P I$ oleh peneliti sebelumnya, yaitu inkonsistensi/kesalahan konsep dan definisi, nilai tidak valid, kesalahan entri, serta missing value, dengan penyesuaian terhadap kondisi studi kasus. Penilaian terhadap variabel-variabel tersebut mengasumsikan bahwa faktor penyebab selain akibat implementasi CAPI diabaikan. Oleh karena itu, dalam merepresentasikan hasil penelitian, perlu memahami asumsi tersebut.

\section{Usability}

Variabel yang digunakan dalam pengkuran ini berkaitan dengan kemudahan pengguna dalam menggunakan sistem CAPI untuk pengumpulan data. Aspek user interface (UI) dan user experience (UX) sangat menentukan pada usability. Komponen-komponen visual yang disajikan oleh aplikasi CAPI, seperti kesesuaian dan konsistensi tombol, tulisan, dan warna, merupakan hal yang dinilai pada aspek UI, sedangkan aspek UX berkaitan dengan kesan atau hal yang dirasakan oleh pengguna secara emosional dalam berinteraksi dengan aplikasi CAPI, seperti reaksi, antusiasme, serta ketertarikan dalam menggunakan aplikasi CAPI.

\section{Pengumpulan Data}

Data mengenai CAPI yang dibutuhkan untuk analisis dikumpulkan dengan tiga jenis pendekatan. Pertama, data empiris mengenai durasi pengisian kuesioner diperoleh dari $\log$ (catatan) khusus yang di-generate oleh aplikasi $C A P I$. Kedua, data mengenai jumlah nonresponse, total responden yang dicacah, serta kesalahan pemasukan/entri data diperoleh dari raw data yang dihaslkan oleh aplikasi CAPI. Data mengenai persepsi pengguna (interviewer) dikumpulkan dengan cara melakukan pencacahan lengkap (sensus) kepada pengguna CAPI (self enumeration), baik mengenai laporan kerusakan dan komplain, maupun kepuasan terhadap user interface dan user experience (QUIS). Sedangkan data yang berkaitan dengan PAPI diperoleh dengan pencatatan manual, baik berupa durasi pencacahan, durasi batching document, serta durasi pengentrian data. 
Waktu pengumpulan data bervariasi sesuai dengan data yang dikumpulkan. Data mengenai kerusakan dan komplain petugas pencacahan dilaporkan setiap hari setelah melakukan kegiatan pencacahan di lapangan. Pada tahapan batching, editing, dan coding kuesioner, serta pengentrian data juga dilakukan pencatatan. Statistik dari raw data yang dihasilkan pada saat tabulasi juga dikumpulkan untuk melihat kualitas data. Pengukuran QUIS dilakukan dengan menyebarkan kuesioner online setelah seluruh kegiatan pencacaan di lapangan selesai dilaksanakan.

Pertanyaan yang harus dijawab oleh interviewer pada QUIS terdiri dari 7 kategori, yaitu:

1. Tanggapan umum terhadap kinerja sistem CAPI

2. Tampilan Layar Monitor

3. Penggunaan Istilah dan Informasi pada Aplikasi

4. Kemudahan Mempelajari Aplikasi

5. Kinerja Sistem

6. Panduan Penggunaan

7. Saran Terkait Hardware dan Software

Petanyaan untuk kategori 1 sampai dengan 6 berbentuk skala likert dengan nilai berupa 1 (respon negatif) hingga 9 (respon positif). Skala likert merupakan skala yang digunakan untuk mengukur sikap, pendapat, dan persepsi seseorang.

\section{Metode Analisis}

Data yang dikumpulkan dari berbagai sumber diolah, divalidasi, dan disajikan secara deskriptif untuk menggambarkan kondisi variabel yang diteliti. Penyajian dititik beratkan pada niai-nilai yang membutuhkan perhatian atau berbeda dari nilai rata-rata, misalnya hal-hal yang mengurangi performa dan kualitas data pada penerapan $C A P I$.

\section{HASIL DAN PEMBAHASAN}

\section{Performance}

Dari proses pencatatan durasi interview, baik pada PAPI maupun CAPI diperoleh hasil rata-rata durasi interview setiap responden dengan menggunakan PAPI pada PKL 54 adalah 1819,749 detik, sedangkan dengan menggunakan CAPI adalah 1531,229 detik. Adapun waktu yang diperlukan mulai dari pencacahan lapangan hingga menghasilkan raw data yang siap disajikan/ditabulasikan untuk keperluan analisis ditunjukkan pada Error! Reference source not found. berikut.

Statistik diatas menunjukkan bahwa CAPI memberikan dampak yang efek yang signifikan terhadap durasi survey, khususnya pada pencacahan dan pengolahan data. Efek terbesar terdapat pada proses Batching, Editing, dan Coding $(B E C)$, di mana CAPI dapat menghemat waktu selama 16 hari. Hal ini memberikan dampak positif dari segi durasi pelaksanaan survey, namun dapat memberikan dampak negative terhadap kualitas isian kuesioner karena proses $B E C$ tidak dilakukan pada CAPI.

Koordinator tim (kortim) memimpin 2 hingga 3 orang interviewer dalam kegiatan pengumpulan data survey. Konfirmasi ke kortim bertujuan untuk memeriksa kepastian isian kuesioner yang tidak valid, anomali, atau terdapat kuesioner yang belum terkirim ke server. Proses tersebut ditindaklanjuti dengan database cleaning untuk memperbaiki data yang terkoreksi. Total waktu 5 hari untuk kedua proses tersebut dapat mengganggu kualitas CAPI, di mana data sedapat mungkin dikoreksi pada saat pencacahan berlangsung atau dalam rentang waktu yang seminimal mungkin dengan pencacahan. Pada PKL 55 diterapkan mekanisme notifikasi di mana setiap pencacah akan menerima pesan untuk memeriksa data yang anomali. Pesan tersebut dibuat oleh Kortim dan dikirimkan ke pencacah yang bersangkutan secara real time (near real time) dengan meggunakan fasilitas yang disediakan oleh sistem CAPI. Dengan demikian, masalah terkait konfirmasi anomali data dapat terselesaikan dalam rentang waktu yang kecil dari proses interview.

Laporan kerusakan/keluhan dari interviewer terkait performa sistem CAPI yang tercatat pada PKL 54 untuk permasalahan software diantaranya adalah masih seringnya terjadi error dan isian Blok 
Tabel 1. Waktu yang diperlukan dari proses pencacahan hingga siap ditabulasikan pada PKL 54

\begin{tabular}{|l|l|l|}
\hline \multicolumn{1}{|c|}{ Rincian } & \multicolumn{1}{c|}{ CAPI } & \multicolumn{1}{c|}{ PAPI } \\
\hline Waktu pencacahan & 7 hari & 7 hari \\
\hline Batching, Editing, Coding & - & 16 hari \\
\hline Entri Data & - & 3 hari \\
\hline Konfirmasi ke koordinator tim & 3 hari & - \\
\hline Database cleaning & 2 hari & - \\
\hline Total Waktu & 12 hari & 26 hari \\
\hline
\end{tabular}

I, yang merupakan kelompok isian identitas responden, yang tidak dapat diedit. Error yang terjadi berupa infinite loop dan force close. Sedangkan untuk permasalahan hardware, terdapat sejumlah laporan terkait gangguan tablet PC yang tidak terdeteksi penyebabnya yang menyebabkan tablet PC tersebut tidak dapat bekerja secara normal. Gangguan seperti ini kemungkinan diakibatkan oleh sistem operasi, atau perangkat keras yang mengalami kegagalan fungsi. Permasalahan lain yang dilaporkan adalah kurang sensitifnya touch screen hardware yang digunakan yang menyulitkan interviewer mengentrikan jawaban responden.

Pada PKL 55, terdapat 25 kasus pengiriman kuesioner yang mengalami software crash (force close) yang menyebabkan kuesioner gagal terkirim, atau sekitar $0,51 \%$ dari total kuesioner yang dicacah dengan CAPI. Kegagalan pengiriman kuesioner yang diakibatkan oleh jaringan internet sebanyak 42 kasus atau sekitar $0,86 \%$, sedangkan kegagalan akibat error pada sisi server sebanyak 24 kasus, atau sekitar 0,5\%. Kasus tidak terdapatnya jaringan internet dapat diatasi dengan penyimpanan offline yang disediakan oleh aplikasi CAPI untuk kemudian dikirimkan ke server apabila sudah terkoneksi ke internet/server. Sedangkan untuk kasus kegagalan akibat error pada sisi server pada PKL 55 merupakan masalah yang diakibatkan oleh adanya perbaikan infrastruktur server yang digunakan pada saat pencacahan sedang berlangsung. Server CAPI yang digunakan di-hosting pada kampus STIS. Dari hasil tersebut, terlihat bahwa masalah yang timbul tidak memberikan dampak yang masif secara kuantitas terhadap pelaksanaan CAPI.

Selain mencatat permasalahan yang timbul, saran terkait hardware dari interviewer juga dicatat yang disajikan pada Error! Reference source not found. berikut ini.

Dari hasil tersebut, sebanyak 77 interviewer, atau 69,4\%, menyatakan bahwa ukuran layar tablet yang digunakan, yakni 10.1 inch, sudah sesuai, dan $19.8 \%$ menyatakan ukuran layar perlu diperkecil namun tidak sampai diperkecil dua kali lipat. Berdasarkan hasil tersebut, untuk pelaksanaan survey sejenis, di mana ratarata interviewer melakukan pencacahan dalam keadaan duduk, ukuran layar tersebut masih memadai atau dapat diperkecil lagi menjadi sekitar 8 inch (ukuran layar standard smartphone yang tersedia di pasaran). Pada aspek berat smartphone, sebagian besar interviewer merasa smartphone, yakni 560 gram, terlalu berat untuk dibawa sehingga perlu dikurangi. Dari segi ketahanan baterai diperlukan penambahan kapasitas sebesar lebih dari dua kali lipat dari kapasitas tablet $P C$ yang digunakan pada PKL 54 dan 55, yaitu 3170 $m A h$ dengan daya tahan 11 hingga 12 jam untuk pemakaian normal.

Saran terkait software pada umumnya terkait dengan tampilan yang akan dibahas pada sub bab usability. Namun, untuk menghindari kegagalan software yang diakibatkan oleh sistem operasi, penulis menyarankan agar sistem operasi diupgrade ke versi tebaru yang didukung oleh hardware yang akan digunakan, dan perlu dilakukan instalasi ulang untuk seluruh device agar environment sistem operasi yang digunakan seragam. 


\section{Ukuran layar smartphone}

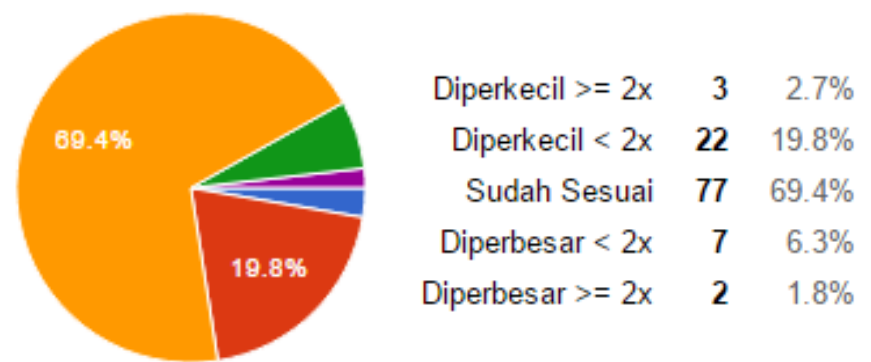

\section{Berat smartphone}

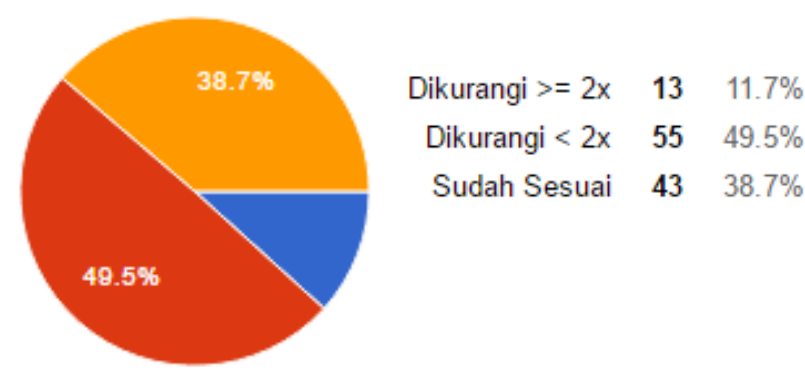

\section{Ketahanan baterai}

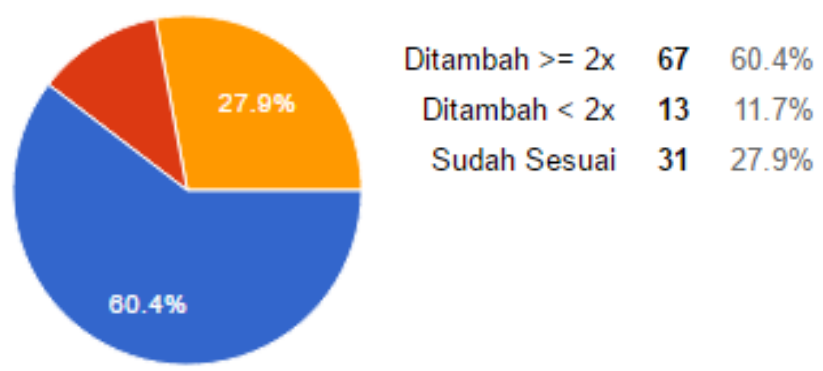

Gambar 3. Hasil survey persepsi interviewer PKL 54 terkait hardware

Dari hasil tersebut, sebanyak 77 interviewer, atau 69,4\%, menyatakan bahwa ukuran layar tablet yang digunakan, yakni 10.1 inch, sudah sesuai, dan $19.8 \%$ menyatakan ukuran layar perlu diperkecil namun tidak sampai diperkecil dua kali lipat. Berdasarkan hasil tersebut, untuk pelaksanaan survey sejenis, di mana ratarata interviewer melakukan pencacahan dalam keadaan duduk, ukuran layar tersebut masih memadai atau dapat diperkecil lagi menjadi sekitar 8 inch (ukuran layar standard smartphone yang tersedia di pasaran). Pada aspek berat smartphone, sebagian besar interviewer merasa smartphone, yakni 560 gram, terlalu berat untuk dibawa sehingga perlu dikurangi. Dari segi ketahanan baterai diperlukan penambahan kapasitas sebesar lebih dari dua kali lipat dari kapasitas tablet $P C$ yang digunakan pada PKL 54 dan 55, yaitu 3170 $m A h$ dengan daya tahan 11 hingga 12 jam untuk pemakaian normal.

Saran terkait software pada umumnya terkait dengan tampilan yang akan dibahas pada sub bab usability. Namun, untuk menghindari kegagalan software yang diakibatkan oleh sistem operasi, penulis menyarankan agar sistem operasi diupgrade ke versi tebaru yang didukung oleh hardware yang akan digunakan, dan perlu dilakukan instalasi ulang untuk seluruh device agar environment sistem operasi yang digunakan seragam. 


\section{Data Quality}

Hasil pemantauan variabel kualitas data pada PKL 54 menunjukkan pada CAPI terdapat 13 isian yang tidak konsisten atau kesalahan konsep dan defininsi, sedangkan pada $P A P I$ terdapat 123 isian. Pada PKL 55 kasus yang serupa terjadi sebanyak 87 kasus atau sekitar 5,1\% dari total kuesioner yang dicacah dengan $C A P I$, sedangkan statistik kuesioner yang dicacah dengan PAPI masih dalam proses pengolahan ketika laporan penelitian ini dibuat. Kesalahan tersebut dapat diakibatkan oleh banyak hal, seperti kesalahan pemahaman konsep oleh pencacah, kesalahan entri, ataupun kesalahan validasi data (routing) pada saat mengisi kuesioner. Kesalahan yang dapat diminimalisir oleh CAPI adalah kesalahan entri, yang divalidasi langsung pada saat pencacahan di lapangan, dan kesalahan routing di mana routing dilakukan secara otomatis oleh aplikasi CAPI.

Untuk lebih menekan jumlah kesalahan pada kasus inkonsistensi atau kesalahan konsep dan definisi, penulis merekomendasikan untuk menambahkan fitur e-learning yang memungkinkan pencacah untuk mempelajari konsep dan definisi dengan mudah melalui aplikasi CAPI. Fitur dapat bersifat pasif, di mana trigger dilakukan oleh interviewer, atau bersifat pasif di mana aplikasi akan memantau dan mempelajari isian yang dientrikan oleh interviewer.

Kasus kesalahan pengentrian (wrong key) data yang tercatat adalah sebanyak 34 kasus pada kuesioner CAPI PKL 54. Kesalahan pengentrian tersebut berupa kesalahan menginputkan Nomor Kode Sampel (NKS). Pada PKL 55, kesalahan tersbut dapat dihilangkan dengan menerapkan mekanisme yang berbeda, di mana pencacah tidak perlu menginputkan NKS, tetapi kuesioner yang sudah dilengkapi dengan NKS dan biodata responden akan secara otomatis di-set oleh sistem CAPI kepada perangkat masingmasing interviewer sesuai dengan sampel yang akan dicacah.

Pada PKL 55, terdapat 39 kuesioner atau sekitar 2,23\% yang mengalami kasus missing value setelah interview dilakukan selama masa pengumpulan data di lapangan. Hal ini disebabkan oleh validasi rentang nilai yang telah ditanamkan pada kuesioner yang mengakibatkan nilai diluar rentang tersebut tidak dapat diterima oleh aplikai CAPI. Hal ini diakibatkan oleh adanya kasus yang tidak terpantau pada saat survey pendahuluan sehingga tidak dihandle oleh desain dan validasi kuesioner. Pada pencacahan dengan PAPI, hal tersebut dapat teratasi dengan adanya proses editing, namun pada CAPI hal tersebut mengakibatkan data tidak dapat diinputkan ke kuesioner digital. Untuk mengatasi hal tersebut, perlu dibuat mekanisme untuk menangkap nilai-nilai diluar rentang yang telah ditetapkan, misalnya memungkinkan untuk tetap mengisikan nilai diluar rentang dengan memunculkan pesan/notifikasi. Pendekatan ideal yang direkomendasikan penulis adalah dengan menerapkan sistem pelaporan berjenjang nilai yang anomali, mulai dari pencacah, Kortim, Intruktur Daerah, Instruktur Nasional, hingga ke subject matter yang diintegrasikan dengan updating validasi kuesioner secara broadcast. Namun, penerapan hal ini perlu dirancang dengan baik, karena melibatkan komunikasi data yang intens antara semua pihak yang terlibat pada pelaksanaan survey.

\section{Usability}

Usability diukur dengan Questionnaire of User Interface Satisfaction. (QUIS). Tanggapan Umum yang diberikan oleh interviewer pada PKL 54 berkisar antara 7 hingga 9 dari skala likert 1 (negatif) hingga 9 (positif). Hal ini menunjukkan bahwa desain kuesioner dengan CAPI secara keseluruhan (overall) sudah sesuai dengan yang diinginkan interviewer. Error! Reference source not found. menunjukkan contoh salah satu variable yang dinilai pada Tanggapan Umum. Hasil selengkapnya dapat dilihat pada Lampiran 2.

Pada bagian Tampilan Layar Monitor hasil QIUS, terdapat 3 hal yang membutuhkan perbaikan tampilan, yaitu:

1. Penggunaan highlighting, yakni Penggunaan warna, ukuran, ketebalan 


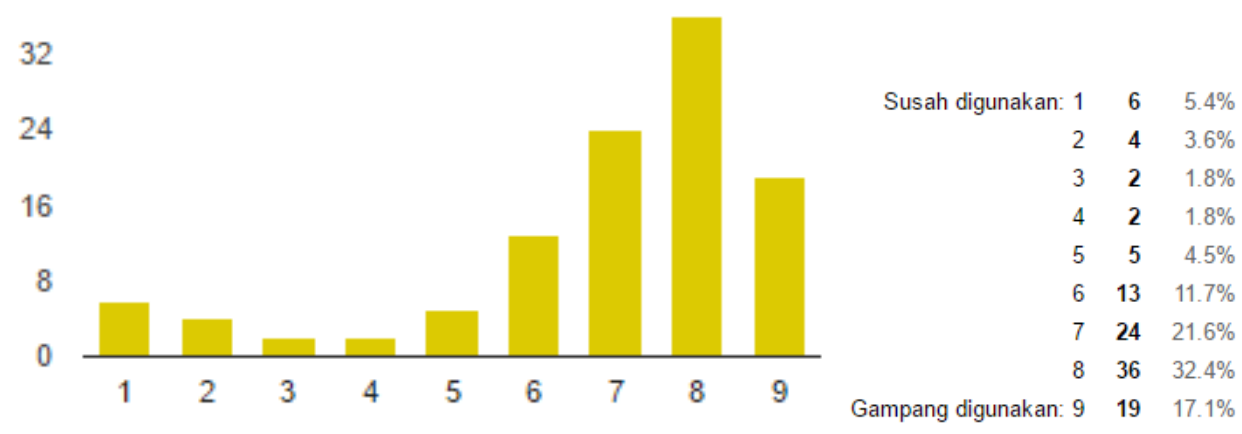

Gambar 4. Hasil survey kemudahan penggunaan CAPI PKL 54

Ukuran huruf/tulisan

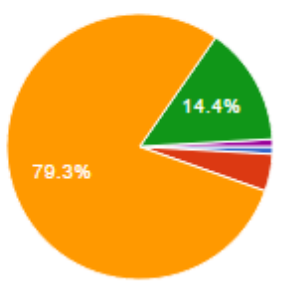

$\begin{array}{rrr}\text { Diperkecil }>=2 \mathrm{x} & \mathbf{1} & 0.9 \% \\ \text { Diperkecil }<2 \mathrm{x} & \mathbf{5} & 4.5 \% \\ \text { Sudah Sesuai } & \mathbf{8 8} & 79.3 \% \\ \text { Diperbesar }<2 \mathrm{x} & \mathbf{1 6} & 14.4 \% \\ \text { Diperbesar }>=2 \mathrm{x} & \mathbf{1} & 0.9 \%\end{array}$

Jumlah informasi/pertanyaan yang muncul dalam satu tampilan pada layar monitor.

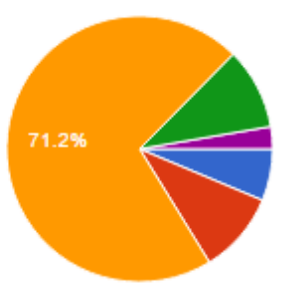

$\begin{array}{rrr}\text { Dikurangi }>=2 x & 7 & 6.3 \% \\ \text { Dikurangi }<2 \mathrm{x} & 11 & 9.9 \% \\ \text { Sudah Sesuai } & 79 & 71.2 \% \\ \text { Ditambah }<2 \mathrm{x} & 11 & 9.9 \% \\ \text { Ditambah }>=2 \mathrm{x} & 3 & 2.7 \%\end{array}$

Gambar 5. Penilaian interviewer PKL 54 terhadap informasi yang ditampilkan aplikasi CAPI pada layar monitor

(bold), dan semacamnya yang bersifat khusus untuk menandai informasi penting,

2. Perlunya kemudahan navigasi kembali ke tampilan sebelumnya, dan

3. Tampilan progress penyelesaian pekerjaan, yakni Tampilan berapa bagian (persen) isian yang sudah dan belum diselesaikan pada aplikasi.

Proses yang membutuhkan waktu tunggu yang lama, seperti upload/download kuesioner perlu dilengkapi dengan progress bar. Selain itu, interviewer juga merasa khawatir untuk mengeskplorasi sendiri fitur-fitur yang ada padi CAPI dengan mekanisme trial and error. Hal ini dikarenakan tidak terdapatnya halaman simulasi dan fitur undo/redo. Untuk itu, pada pengembangan CAPI perlu ditambahkan fitur tersebut untuk menghasilkan user experience yang lebih baik terhadap aplikasi CAPI. Karena keterbatasan jumlah halaman, statistik pendukung pembahasan di atas tidak disertakan dalam tulisan ini.

Keluhan yang juga diutarakan oleh interviewer adalah fitur auto correct dan auto complete yang mengakibatkan tulisan yang diinput pencacah diubah secara otomatis oleh sistem sehingga tidak sesuai dengan yang diharapkan. Fitur tersebut perlu di-non-aktifkan atau menggunakan field input yang tidak terpangaruh oleh auto complete. Informasi yang tercakup pada panduan pengguna juga perlu dibuat lebih informatif agar mudah dipahami secara cepat oleh interviewer. Informasi yang ditampilkan pada aplikasi CAPI perlu dibedakan dengan buku panduan yang digunakan saat pelatihan dengan 
mempertimbangkan efisiensi dan keterbatasan ukuran layar hardware.

Keterbatasan dimensi layar monitor pada CAPI membuat desain kuesioner perlu disesuaikan sehingga informasi yang tampil pada layar monitor dapat terbaca dengan jelas oleh interviewer. Error! Reference source not found. menunjukkan hasil QUIS untuk penilaian interviewer terhadap informasi yang ditampilkan aplikasi CAPI pada layar monitor.

Berdasarkan hasil tersebut, ukuran huruf dan jumlah informasi yang ditampilkan pada satu tampilan layar monitor sudah sesuai sehingga bisa terbaca dengan jealas oleh interviewer. Adapun ukuran huruf yang digunakan berkisar antara 12 hingga 14 point (pt) dan jumlah pertanyaan pada satu kali tampilan berkisar antara 4 hingga 7 pertanyaan.

\section{KESIMPULAN DAN SARAN}

\section{Kesimpulan}

Berdasarkan studi literatur yang dilakukan pada penelitian ini, yakni mengenai implementasi CAPI di berbagai negara selama 15 tahun terakhir, terdapat 3 kelompok variabel yang dapat digunakan sebagai ukuran keberhasilan penerapan CAPI pada kegiatan pengumpulan data, yakni system performance, data quality, dan usability. Hasil dari pilot study yang dilakukan, yakni pada PKL 54 dan 55, menunjukkan bahwa CAPI dapat memberikan performa yang lebih baik dibandingkan dengan PAPI, khususnya dalam hal durasi proses pencacahan hingga pengolahan data. Sistem notifikasi berjenjang antara Kortim dan pencacah dapat membantu Kortim memonitor kesalahan isian oleh pencacah sehingga mengoptimalkan peran Kortim.

Dari segi kualitas data, penggunaan CAPI dapat memberikan validasi data yang lebih baik dengan pengetrian dan validasi data melalui aplikasi di lapangan dan adanya fitur automatic routing yang meminimalisir inkonsistensi isian kuesioner. Namun, kendala kesulitan mengentri data pada device yang memiliki alat input yang kurang ergonomis merupakan hambatan yang mengganggu performa dan dapat menurunkan kualitas data yang dihasilkan dengan $C A P I$.

Desain antarmuka pada CAPI yang dikembangkan oleh STIS secara umum mendapat tanggapan positif dari interviewer yang menggunakan. Adapun beberapa hal yang menjadi masukan untuk meningkatkan usability dari CAPI STIS, diantara adalah penambahan fasilitas undo/redo serta simulasi aksi yang akan dilakukan pada aplikasi, dan menghindari pengaruh fitur auto complete dan auto correct pada saat pengentrian isian kuesioner CAPI.

Secara garis besar, desain CAPI yang diterapkan dan telah diujicoba pada pilot study, dengan jumlah sampel yang cukup representatif untuk menguji sistem CAPI, telah siap untuk digunakan dalam survey skala besar. Pengaruh negative CAPI terhadap variabel-variabel yang diteliti tidak signifikan dibandingkan dengan pengaruh positif yang diberikan dibandingkan dengan PAPI yang selama ini diterapkan.

\section{Saran}

Penelitian ini telah menghasilkan sejumlah instrument untuk mengukur kinerja CAPI dari berbagai aspek. Namun, pada penelitian ini masih terdapat beberapa keterbatasan, baik dari segi persiapan pencatatan data yang dibutuhkan, maupun jumlah variabel yang diamati. Oleh karena itu, selain mempelajari hasil pengolahan data dan analisis dari penelitian ini, hasil studi literatur pada penelitian ini sebaiknya dimanfaatkan pembaca sebagai referensi hal-hal yang perlu diperhatikan pada penerapan CAPI. Demikian pula untuk penelitian selanjutnya agar dapat meneliti variabel yang lebih lengkap seperti yang dipaparkan penulis pada bab studi literatur.

Penelitian dan beberapa penelitian sebelumnya masih menghasilkan beberapa issue terkait penerapan CAPI serta masih terdapatnya kelemahan pada PAPI yang belum teratasi, misalnya untuk kasus kesalahan konsep oleh pencacah yang menyebabkan kesalahan isian. Hal tersebut memiliki dampak negatif pada CAPI karena akan menghasilkan routing yang salah dan 
tidak adanya bukti tertulis/analog sebagai backup. Tentu hal tersebut perlu diteliti lebih lanjut untuk menemukan solusinya. Kasus terdapatnya nilai diluar rentang validasi juga merupakan contoh lain yang perlu diperhatikan, misalnya dengan menerapkan sistem pelaporan dan updating range validasi berjenjang.

Meskipun penerapan sistem notifikasi dari dan ke Kortim dapat menghasilkan validasi yang berlapis pada $C A P I$, namun pada studi kasus PKL di STIS, beban Kortim menjadi lebih berat karena memiliki tanggung jawab membackup pekerjaan pencacah. Sebaiknya pada PKL selanjutnya, atau kegiatan survey yang menerapkan sistem ini, tanggungjawab Kortim sebagai backup dari pencacah perlu dihilangkan, dan digantikan dengan pencacah cadangan selain Kortim.

\section{DAFTAR PUSTAKA}

Baker, R.P. (1992): New Technology in Survey Research: Computer-Assisted Personal Interviewing (CAPI). Social Science Computer Review, 10, 145157.

Baker, R.P., Bradburn, N., and Johnson, R. (1994): CAPI: An Experimental Evaluation. In American Statistical Association (Ed.), Proceedings of the Sec- tion on Survey Research Methods, 851-855.

Baker, R. P., Bradburn, N. M., \& Johnson, R. A. (1995). Computer-assisted personal interviewing: an experimental evaluation of data quality and cost. Journal of Official Statistics, 11(4), 413-431.

Bernabe-Ortiz, A., Curioso, W. H., Gonzales, M. A., Evangelista, W., Castagnetto, J. M., Carcamo, C. P., ... \& Holmes, K. K. (2008). Handheld computers for self-administered sensitive data collection: a comparative study in Peru. BMC medical informatics and decision making, 8(1), 11

Bishop, Yvonne M., Warren L. Buckler, Robert P. Parker, and Charles E. Caudill. 1990. "Computer Assisted
Survey Information Collection." (April).

Caviglia-harris, Jill et al. 2012. "Improving Household Surveys Through Computer-Assisted Data Collection: Use of Touch-Screen Laptops in Challenging Environments."

Chalmers, Neil, and Joachim De Weerdt. 2010. "A Comparison of CAPI and PAPI through a Randomized Field Experiment." (November):1-56.

Childs, J. H., \& Landreth, A. (2006). Analyzing interviewer/respondent interactions while using a mobile computer-assisted personal interview device. Field methods, 18(3), 335351.

Couper, Mick P., and Geraldine Burt. 1989. "THE IMPACT OF COMPUTERASSISTED PERSONAL INTERVIEWING (CAPI) ON INTERVIEWER PERFORMANCE: THE CPS EXPERIENCE." 189-93.

Couper, M.P. and Groves, R.M. (1992): Interviewer reactions to alternative hardware for computer-assisted personal interviewing. Journal of Official Sta- tistics, 8, 201-210.

Couper, M. P. (2000). Usability evaluation of computer-assisted survey instruments. Social Science Computer Review, 18(4), 384-396.

De Leeuw, E. D. 1993. "Data Quality in Mail, Telephone, and Face to Face surveys".

Fuchs, Marek, Mick P. Couper, and Sue Ellen Hansen. 2000. "Technology Effects : Interview Duration in CAPI and Paper and Pencil Surveys."

Lynn, P., \& Purdon, S. (1994). Time-series and lap-tops: the change to computerassisted interviewing. INTERNATIONAL SOCIAL ATTITUDES, 141-141.

Manners, Tony. $1990 . \quad$ “THE DEVELOPMENT OF COMPUTER ASSISTED INTERVIEWING ( CAI ) FOR HOUSEHOLD SURVEYS : THE CASE OF THE BRITISH LABOUR FORCE SURVEY."

Martin, J. (1993, October). PAPI to CAPI: the OPCS experience. In Essays on 
Blaise 1993: Proceedings of the Second International Blaise Users Conference, Office of Population Censuses and Surveys, London (pp. 96-117).

Matheson, Jil. 1991. “APPLICATION OF COMPUTER ASSISTED INTERVIEWING TO THE FAMILY EXPENDITURE SURVEY." (February):1-48.

Müller, S., \& Kesselmann, P. (1996). Akzeptanz von computergestützten Erhebungsverfahren. Ein empirischer Vergleich mit der traditionellen Fragebogentechnik. Marketing ZFP, 18(3), 191-202.

Randolph, Justus J., Marjo Virnes, Ilkka Jormanainen, and Pasi J. Eronen. 2006. "The Effects of a ComputerAssisted Interview Tool on Data Quality." 9:195-205.

Sainsbury, Roy, John Ditch, and Sandra Hutton. 1993. "Computer Assisted Personal Interviewing.” (3).

Sainsbury, Roy, John Ditch, and Sandra Hutton. 1995. "The Effect of Computer-Assisted Interviewing on Data Quality: A Review."

Shaw, Arthur, Lena Nguyen, and Ulrike Nischan. 2011. "Comparative Assessment of Software Programs for the Development of ComputerAssisted Personal Interview ( CAPI ) Applications." (July).

Slaughter, Laura, Ben Harper, and Kent Norman. 1994. "Assessing the Equivalence of the Paper and On-Line Formats of the QUIS 5 . 5."

Wensing, Fred, Jane Barresi, David Finlay, and Australian Bureau. 2003. "Developing an Optimal Screen Layout for CAI." 63-76. 
